\author{
Лукьяненко Виктор Павлович, Муханова Наталья Владимировна, \\ Коляко Елена Владимировна
}

\title{
ФИТБОЛ-ГИМНАСТИКА КАК СРЕДСТВО СОХРАНЕНИЯ И УКРЕПЛЕНИЯ ЗДОРОВЬЯ ШКОЛЬНИКОВ НА УРОКАХ ФИЗИЧЕСКОЙ КУЛЬТУРЫ
}

Больиую популярность среди икольников получалот новые формы занятий по физической культуре. С челью повышения интереса и мотивации обучающихся элементы некоторых новых форм занятий физическими упражнениями можно включать в содержсание уроков физической культуры. K таковым можно отнести фитбол-гимнастику. Это одна из новых форм занятий, относяицихся коздоровительной гимнастике. В настоящее время суцествуют различные оздоровительные програимы по фитбол-гимнастике, элементы которых можсо применять на уроках по физической культуре с целью сохранения и укрепления здоровья обучающихся.

Ключевые слова: оздоровительная гимнастика, интерес, мотивация, урок физической культуры, фитбол-гимнастика, функциональная подготовка, физическая подготовка, физическое развитие.

\section{Victor Lukyanenko, Natalia Mukhanova, Elena Coleco \\ FITBALL GYMNASTICS AS A MEAN OF KEEPING AND IMPROVEMENT OF SCHOOLCHILDREN'S HEALTH ON PE LESSONS}

New forms of PE studies get big popularity among schoolchildren. With the aim of increasing of schoolchildren 's interest and motivation, elements of some new forms of studies with physical exercises can be included in contents of PE lessons. It can be football-gymnastics. This is one of new forms of studies relating to improving gymnastics. These days there are different health programmes on football-gymnastics, which elements can be used on the lessons of physical culture with the aim of keeping and improving of schoolchildren's health.

Key words: Improving gymnastics, interest, motivation, PE lesson, football-gymnastics, functional preparation, physical preparation, and physical development.

Bведениe /Introduction. В настоящее время накапливается всё больше данных, свидетельствующих о недостатках в физическом развитии населения страны, что является одной из основных причин низкого уровня состояния здоровья людей. В этой связи особого внимания заслуживает проблема ухудшения состояния здоровья детей и подростков в период обучения в школе.

Двигательная активность - важнейший фактор сохранения и укрепления здоровья, поэтому большое внимание должно быть уделено качественной организации процесса физического воспитания школьников. При этом первоочередная роль в вопросах здоровьесбережения обучающихся принадлежит урокам физической культуры.

В условиях новых требований к качеству физкультурного образования школьников, учителям физической культуры необходимо применять более современные подходы, средства и методы организации учебных занятий оздоровительной направленности, содержание которых определено ФГОС общего образования, и должно учитывать интересы обучающихся и их родителей [6].

С целью определения наиболее популярных средств физической культуры, способствующих сохранению и укреплению здоровья в 2016 / 2017 учебном году на базе МБОУ СОШ № 1 был проведён опрос учащихся (5 класс) и их родителей. Более $70 \%$ респондентов в качестве приоритетного вида физических упражнений оздоровительной направленности выбрали фитбол-гимнастику.

С учётом вышеизложенного актуальность нашего исследования обусловлена необходимостью совершенствования учебного процесса по физической культуре в школе с применением современных, усовершенстваованных средств физической культуры оздоровительной направленности. 
Maтериалы и методы / Materials and methods. Фитбол-гимнастика - это вид оздоровительной гимнастики с использованием больших гимнастических мячей (фитболов). Результатами многочисленных исследований доказано, что упражнения с их использованием оказывают положительное влияние на физическое и психоэмоциональное состояние обучающихся и способствуют повышению их интереса к урокам физической культуры $[1,5]$.

Объектом исследования был определен учебный процесс по физической культуре в основной школе.

Предметом исследования - методика организации и проведения учебных занятий по физической культуре с применением средств фитнес-гимнастики.

Целью исследования стали разработка и обоснование методики организации уроков физической культуры в основной школе с применением средств фитбол-гимнастики.

Для достижения цели исследования были поставлены следующие задачи:

1) изучить и обобщить данные научно-методической литературы по использованию средств фитбол-гимнастики в учебном процессе по физической культуре;

2) выявить особенности применения средств фитбол-гимнастики в учебном процессе по физической культуре в основной школе;

3) разработать методику организации уроков физической культуры в основной школе с применением средств фитбол-гимнастики;

4) экспериментально обосновать эффективность влияния средств фитбол-гимнастики на повышение функциональной и физической подготовки обучающихся основной ступени обучения.

Была выдвинута гипотеза: проведение уроков физической культуры по разработанной нами экспериментальной методике позволит повысить интерес обучающихся к занятиям физическими упражнениями, уровень их функциональной и физической подготовленности при соблюдении следующих организационно-методических условий организации уроков физической культуры:

- средства фитбол-гимнастики применять во вводной и заключительной частях уроков физической культуры;

- в качестве основных средств фитбол-гимнастики использовать основные (базовые) движения аэробики; физические упражнения, направленные на профилактику и коррекцию нарушений опорно-двигательного аппарата;

- не реже чем раз в неделю использовать музыкальное сопровождение занятий;

- осуществлять систематический контроль за выполнением обучающимися физических упражнений, нормированием физической нагрузки с учетом индивидуальных особенностей занимающихся, вооружать знаниями и умениями самоконтроля;

- опираться на принципы наглядности, систематичности, последовательности, непрерывности, доступности, учёта возрастных и индивидуальных особенностей обучающихся.

Для разработки экспериментальной методики средства фитбол-гимнастики подбирались в соответствии с уровнем физической подготовленности, состояния здоровья, а также $\mathrm{c}$ учётом психолого-физиологических и возрастных особенностей обучающихся.

С целью определения эффективности экспериментальной методики было организовано педагогическое исследование. Сформированы две группы обучающихся 11-12 лет: экспериментальная (ЭГ) и контрольная (КГ). С учащимися КГ занятия проводились по традиционной методике, а в ЭГ уроки физической культуры проходили по специально разработанной методике, основанной на использовании средств фитбол-гимнастики.

Применялись такие методы исследования, как: анализ научно-методической литературы, педагогическое наблюдение; социолого-педагогическое исследование; тестирование уровня развития физических качеств, функционального состояния школьников, их физического развития; педагогический эксперимент; методы математической статистики. 
Pезультаты и обсуждение / Results and discussion. Тестирование уровня развития физических качеств обучающихся представляет собой применение системы специально подобранных физических упражнений. Педагогическое тестирование организовано с целью определения влияния методики комплексного воздействия физических упражнений фитбол-гимнастики на развитие физических качеств школьников основной ступени обучения, участвующих в эксперименте.

Результаты тестирования уровня развития физических качеств у обучающихся ЭГ и КГ на начало и после педагогического исследования представлены на рис 1.

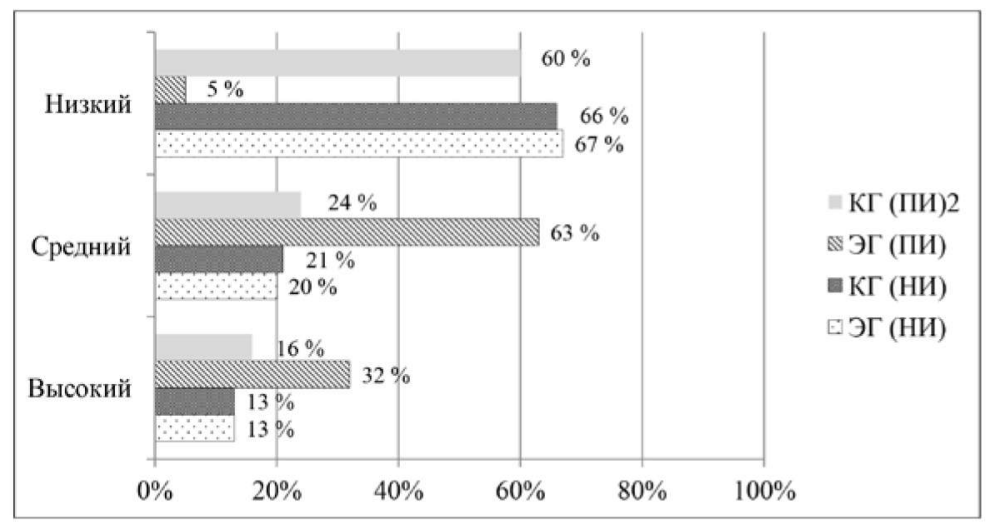

Рис. 1. Результаты исследования уровня развития физических качеств у обучаюшихся ЭГ и КГ

Из рис. 1 видно, что на начало исследований в среднем $13 \%$ учащихся ЭГ и КГ имели высокий и $20 \%$ - средний уровень развития физических качеств. После эксперимента в ЭГ эти показатели достоверно увеличились (высокий уровень - увеличение на $19 \%$, средний уровень увеличение на $43 \%$ за счёт уменьшения с низким - на $62 \%$ ), в то время как в КГ количество школьников с высоким и средним уровнями развития физических качеств увеличилось на $3 \%$ за счёт уменьшения с низким - на $6 \%$.

Для определения количества обучающихся КГ и ЭГ, имеющих гармоничное и дисгармоничное физическое развитие обрабатывались результаты ежегодного медицинского осмотра обучающихся (рост, вес), в котором мы принимали непосредственное участие. Данные физического развития обучающихся КГ и ЭГ представлены на рис. 2.

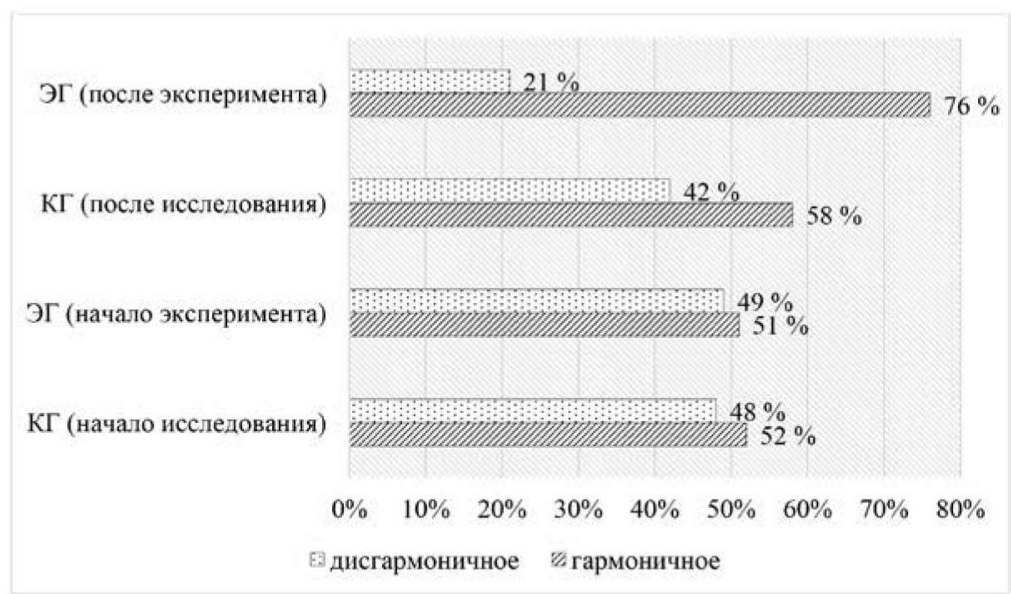

Рис. 2. Показатели физического развития обучающихся КГ и ЭГ 
Из рис. 2 видно, что на начало исследований в среднем 51 \% учащихся ЭГ и КГ имели гармоничное физическое развитие, после эксперимента в ЭГ эти показатели увеличились на $25 \%$, в то время как в КГ они увеличились на $6 \%$.

Заключение / Conclusion. В результате применения экспериментальной методики достоверными оказались изменения следующих показателей:

- ЭГ увеличилось количество школьников с высоким и средним уровнем развития физических качеств на $62 \%$ (с 33 \% до $95 \%$ ), в КГ прирост составил $6 \%$ (с 34 \% до $40 \%$ );

- гармоническое физическое развитие на начало педагогического исследования имели в среднем $51 \%$ обучающихся КГ и ЭК, на заключительном этапе исследования эти показатели стали выше в ЭГ на $25 \%$, в то время как в КГ - на $6 \%$.

В целом результаты исследования показали, что экспериментальная методика, основанная на применении средств фитбол-гимнастики во вводной и заключительной частях уроков физической культуры в основной школе, позволяет существенно повысить у обучающихся уровень физического развития, оказывает положительное влияние на физическое развитие (достоверность $<0,05$ ). Полученные результаты исследования свидетельствуют о целесообразности и высокой эффективности использования средств фитбол-гимнастики на уроках физческой культуры в основной школе.

\section{ЛИТЕРАТУРА И ИНТЕРНЕТ-РЕСУРСЫ}

1. Овчинникова Т. С., Потапчук А. А. Двигательный игротренинг для дошкольников. СПб.: Речь, 2002. $176 \mathrm{c}$.

2. Овчинникова Т. С., Баряева Л. Б., Черная О. В. Игры, занятия и упражнения с мячами: учебное пособие. СПб.: КАРО, 2014. 168 с.

3. О Стратегии государственной молодежной политики в Российской Федерации: Распоряжение Правительства РФ от 18.12.2006 № 1760-р [Электронный ресурс] URL: http://pravo.levonevsky.org/ bazaru09/raspor/sbor12/text12164.htm.

4. Суворова В. С., Чечелева А. А. Фитбол-гимнастика - новая форма оздоровительных занятий по физическому воспитанию // Сборник материалов V Международной научно-практической конференции «Молодежь - науке: образование, здоровье, экология - 2015». С. 78-80.

5. Тихомирова И. В. Фитнес для ленивых: фитбол дома. СПб.г: Невский проспект, 2004. 160 с.

6. Федеральный государственный образовательный стандарт основного общего образования от 17 декабря 2010 г. № 1897 (в ред. Приказов Минобранауки России от 29.12.2014 № 1644).

7. Щенкова И. П. Гимнастика (Занятия с фитболом): метод. рекоменд. к практ. занятиям / И. П. Щенкова, Н. А. Клюкина, И. Е. Басалгина, О. Ю. Маслаускене. Пермь: ФГБОУ ВПО Персмская ГСХА, 2015. $38 \mathrm{c}$.

\section{REFERENCES AND INTERNET RESOURCES}

1. Ovchinnikova T. S., Potapchuk A. A. Dvigatel'nyj igrotrening dlya doshkol'nikov (Motor gaming for preschoolers). SPb.: Rech', 2002. 176 p.

2. Ovchinnikova T. S., Baryaeva L. B., CHernaya O. V. Igry, zanyatiya i uprazhneniya s myachami: uchebnoe posobie (Games, classes and exercises with balls: tutorial). SPb.: KARO, 2014. 168 p.

3. O Strategii gosudarstvennoj molodezhnoj politiki v Rossijskoj Federacii Rasporyazhenie: Pravitel'stva RF ot 18.12.2006 № 1760-r. URL: http://pravo.levonevsky.org/bazaru09/raspor/sbor12/text12164.htm.

4. Suvorova V. S. CHechelevaA. A. Fitbol-gimnastika-novaya forma ozdorovitel'nyh zanyatij po fizicheskomu vospitaniyu (Fitball-gymnastics-a new form of health training in physical education) // Sbornik materialov V mezhdunarodnoj nauchno-prakticheskoj konferencii «Molodezh' - nauke: obrazovanie, zdorov'e, ehkologiya - 2015». P. 78-80.

5. Tihomirova I. V. Fitnes dlya lenivyh: fitbol doma (Fitness for the lazy: fitball at home). SPb.: Nevskij prospekt, 2004. $160 \mathrm{p}$. 
6. Federal'nyj gosudarstvennyj obrazovatel'nyj standart osnovnogo obshchego obrazovaniya ot 17 dekabrya 2010 g. № 1897 (v red. Prikazov Minobranauki Rossii ot 29.12.2014 № 1644).

7. SHCHenkova I. P. Gimnastika (Zanyatiya s fitbolom): metodicheskie rekomendacii k prakticheskim zanyatiyam (Gymnastics (classes with fitball): guidelines for practical classes) / I. P. SHCHenkova, N. A. Klyukina, I. E. Basalgina, O. YU. Maslauskene. Perm': FGBOU VPO Persmskaya GSKHA, 2015. 38 p.

\section{СВЕДЕНИЯ ОБ АВТОРАХ}

Лукьяненко Виктор Павлович, доктор педагогических наук, профессор, профессор кафедры теории и методики физической культуры и спорта СКФУ (Северо-Кавказский федеральный университет) г. Ставрополь, Россия. E-mail: viktor246@mail.ru

Муханова Наталья Владимировна, учитель физической культуры МБОУ НОШ № 24 (Муниципальное бюджетное общеобразовательное учреждение «Начальная общеобразовательная школа № 24» г. Михайловска), аспирант СКФУ. E-mail: uspehnatalja@mail.ru

Коляко Елена Владимировна, учитель физической культуры МБОУ СОШ № 1 (Муниципальное бюджетное общеобразовательное учреждение «Средняя об̆щеобразовательная школа № 1» г. Михайловска), магистрант СКФУ. E-mail: elkatahta@bk.ru

\section{INFORMATION ABOUT AUTHORS}

Lukyanenko Viktor, Doctor of Pedagogical Sciences, Professor, Professor of Department of theory and methodology of physical culture and sports of NCFU (North-Caucasus Federal University) Stavropol, Russia. E-mail: viktor246@mail.ru

Mukhanova Natalia, teacher of physical culture of Municipal budgetary educational establishment the «Initial comprehensive school № 24» of the town of Mikhaylovsk, postgraduate NCFU. E-mail: uspehnatalja@ mail.ru

Coleco Elena, teacher of physical culture of Municipal budget educational institution «Secondary school № 1» the city of Mikhaylovsk, graduate student SKFU. E-mail: elkatahta@bk.ru 